\title{
Comparative Study of Infiltration of Lidocaine with Adrenaline versus Sterile Water in Type 1 Tympanoplasty Performed under General Anaesthesia
}

\author{
Santosh Uttarkar Pandurangarao, ${ }^{1}$ Sridurga Janarthanan ${ }^{1}$
}

\begin{abstract}
Introduction:
It is a common practice to infiltrate 2\% lignocaine with 1:2,00,000 adrenaline for Type 1 Tympanoplasty, even when the surgery is done under general anaesthesia. The purpose of this study is to evaluate the necessity of infiltration of lidocaine with adrenaline (2\% lidocaine with 1:2,00,000 adrenaline) in Type 1 Tympanoplasty surgeries performed under general anaesthesia in terms of per-operative bleeding and post-operative pain relief.

Materials and Methods:

A double blinded, prospective randomized comparative study was conducted in a tertiary care centre. A total of 50 patients planned for Type 1 Tympanoplasty under general anaesthesia, for chronic otitis media, inactive, mucosal disease were selected and divided into two groups randomly. Group A (25 patients) received local infiltration of 2\% Lidocaine with 1:2,00,000 adrenaline and Group B (25 patients) patients received infiltration of sterile water. The per-operative bleeding and postoperative pain relief were assessedat $2 \mathrm{nd}$, 4 th and 6 th post-operative hour in both the groups and the results were analysed.

$\underline{\text { Results: }}$

$P$ value for per operative bleeding was $<0.77$ (non-significant). And the P value for post-operative pain relief at 2 nd hour was $<0.002$ (significant). But the P value for 4 th $(<0.133)$ and 6 th $(<0.358)$ post-operative hours were not significant.

Conclusion:

Infiltration of 2\% lidocaine with 1:2,00,000 adrenaline, doesn t have any significant impact in per-operative bleeding and postoperative pain relief at 4 th and 6th hour. But there is a significant pain relief, for 2 hours after surgery, when 2\% lidocaine with 1:2,00,000 adrenaline is used for infiltration.

Keywords:
\end{abstract}

$\underline{\text { ABSTRACT }}$

Lidocaine; Infiltration, Anesthesia, General; Tympanoplasty

$\mathrm{I}$ n Otolaryngology the quality of anaesthesia is important, as it determines the field of surgery and hence it's outcome.

Type 1 Tympanoplasty is a common surgery, performed for chronic otitis media in inactive mucosal type, where there is tympanic membrane perforation with intact ossicular chain. The procedure includes inspection of middle ear cleft with closure of tympanic membrane

1 - Department of ENT, Rajiv Gandhi University of Health Sciences,

Corresponding author:

Dr Sridurga Janarthanan

email: jsdurga2020@gmail.com perforation with a graft (most commonly used graft is autologous temporalis fascia).

It is a common practice to infiltrate lidocaine with adrenaline ( $2 \%$ lidocaine with 1:2,00,000 adrenaline), even when surgeries are performed under general anaesthesia, and lidocaine is merely considered to be a carrier of adrenaline. ${ }^{1}$

The purpose of this study is to evaluate the necessity of infiltration of lidocaine with adrenaline ( $2 \%$ lidocaine with 1:2,00,000 adrenaline) in Type 1 Tympanoplasty performed under general anaesthesia in terms of peroperative bleeding and post-operative pain relief. 


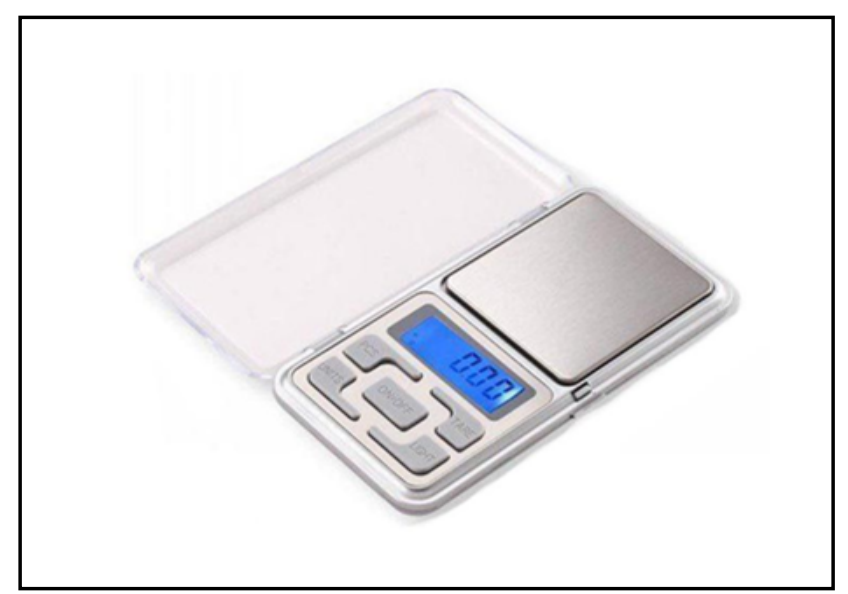

Fig. 1. HMT company weighing apparatus

\section{Materials and Methods}

This is a prospective, randomised, double blinded, comparative study, done in a tertiary care hospital. After obtaining an institutional ethical committee clearance, this study was conducted on 50 patients, who were willing to participate in the study. A written and oral consent was obtained from the patients. The study period was between October 2016 to October 2017.

50 patients who were undergoing Type 1 Tympanoplasty under general anaesthesia, between the age group of 17 to 60 years were included in the study. These patients were randomised into two groups, Group A - the patients with even serial numbers and Group B - patients with odd serial numbers. Group A - 25 patients were infiltrated with $2 \%$ lidocaine with $1: 2,00,000$ adrenaline and Group B - 25 patients were infiltrated with sterile water infiltration.

Patients with co-morbid conditions were excluded from the study. After obtaining the background data from the patients, regular pre-operative investigations were done, including pure tone audiometry.

All these patients were operated by a single surgeon to maintain uniformity. The surgeon and the assisting staff on one side, and the person who measured the intra operative blood loss and post-operative pain score (using VAS) were blinded. Hence making the study double blinded.

General anaesthesia was induced with $0.05 \mathrm{mg} / \mathrm{kg}$ body weight of midazolam, $2 \mathrm{mg} / \mathrm{kg}$ body weight of fentanyl and $2 \mathrm{mg} / \mathrm{kg}$ body weight of propofol. Then, preoxygenation with facemask ventilation was given. Patients were paralysed with vecuronium at the dose of $0.05-1 \mathrm{mg} / \mathrm{kg}$. Endotracheal intubation was done with appropriate size endotracheal tube. Anaesthesia was maintained with nitrous oxide and oxygen at the ratio of 1:2 along with $2 \%$ isoflurane/halothane. Vitals were monitored throughout the surgery. The intra operative Blood Pressure was maintained between 100 - 110 $\mathrm{mmHg}$ (systolic) and $60-70 \mathrm{mmHg}$ (diastolic).

Type 1 Tympanoplasty was done by post aural approach. Patients under Group A were infiltrated with $2 \%$ lidocaine with $1: 2,00,000$ adrenaline, in post

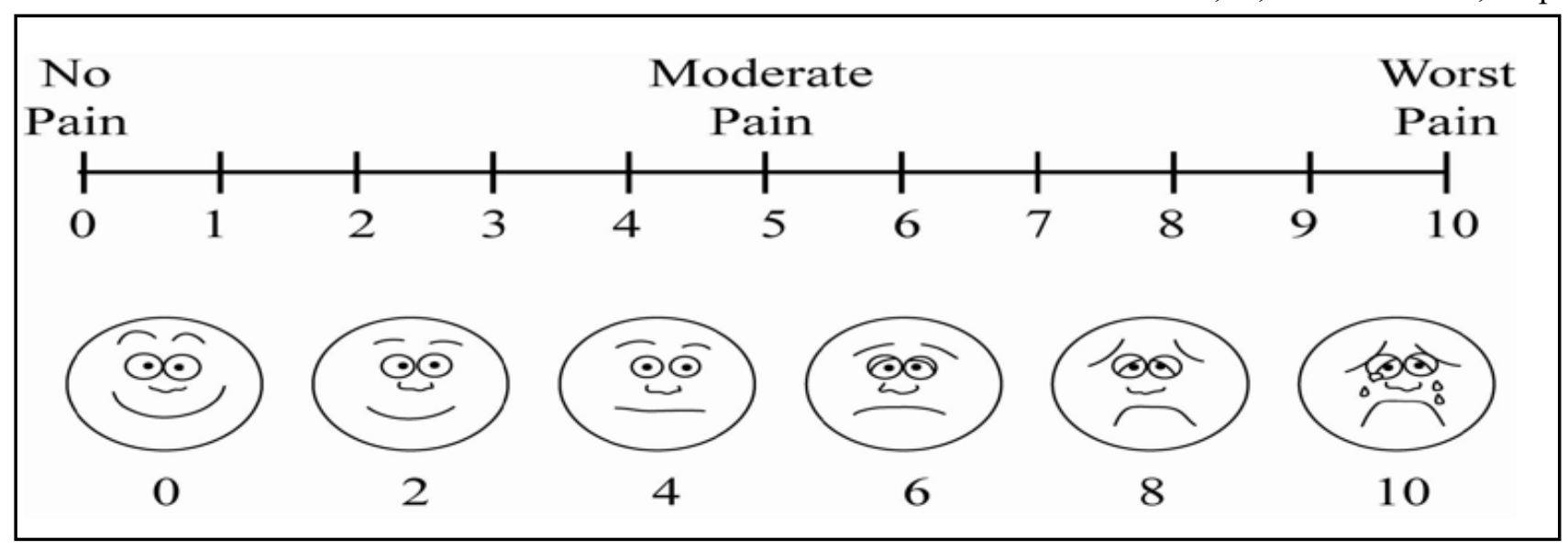

Fig. 2. Visual analogue scale 
Table I: Duration of surgery in Group A and Group B

\begin{tabular}{|c|c|c|c|c|}
\hline \multicolumn{5}{|c|}{ DURATION OF SURGERY(MINS) } \\
\hline GROUPS & MEAN & $\begin{array}{c}\text { STD. } \\
\text { DEVIATION }\end{array}$ & T VALUE & P VALUE \\
\cline { 1 - 3 } Group A & 72.4 & 15.75 & \multirow{2}{*}{0.73} & \multirow{2}{*}{ P $<0.470$} \\
\hline Group B & 69.4 & 13.25 & & \\
\hline
\end{tabular}

auricular region and in external auditory canal around 6 to $8 \mathrm{ml}$ (according to the body weight of the patient). Whereas, patients in Group B were infiltrated with 6 to $8 \mathrm{ml}$ of sterile water.

The per operative bleeding was assessed under aseptic precautions, by measuring the difference of weight between blood stained gauze and dry gauze used during surgery, (with the help of HMT company weighing apparatus with ISI mark and a sensitivity of $0.1 \mathrm{gm}$ to $500 \mathrm{gm}$.), $1 \mathrm{gm}$ difference of weight was taken as $1 \mathrm{ml}$ blood loss (Fig. 1) and by measuring the quantity of blood in suction apparatus before and after surgery. ${ }^{2}$

The post-operative pain was assessed using visual analogue scale with 10 points at $2 \mathrm{nd}, 4$ th, and 6 th postoperative hours (Fig. 2). No analgesics were given intra operatively and 6 hours post operatively in both the groups. Oral analgesics were started after 6 hours of surgery.

The time elapsed between intubation and extubation was considered as the duration of surgery. And the mean time was calculated in both the groups.

\section{Results}

The data was analysed using SPSS (version22.0) software. The age distribution of the study population was between 17 to 60 years, with a mean age of 29 years.

The number of female patients were more in both the groups. The total percentage of female patients were $64 \%$.

The mean duration of surgery in Group A was 72.4 minutes and in Group B was 69.4 minutes. The $P$ value was $<0.470$, which is not significant (Table I). This implies that there was no variation in the duration of surgery between both the groups.

The mean blood loss during the surgery in Group A was $27.6 \mathrm{ml}$ and in Group B was $26.8 \mathrm{ml}$, with a P value of $<0.77$ (non-significant). (Table II)

The post-operative pain score was taken using visual

Table II: Total blood loss in Group A and Group B

\begin{tabular}{|c|c|c|c|c|}
\hline \multicolumn{5}{|c|}{ TOTAL BLOOD LOSS(ML) } \\
\hline GROUPS & MEAN & $\begin{array}{c}\text { STD. } \\
\text { DEVIATION }\end{array}$ & \multirow{2}{*}{ T VALUE } & P VALUE \\
\cline { 1 - 3 } Group A & 27.62 & 12.29 & \multirow{2}{*}{0.29} & \multirow{2}{*}{ P $<0.77$} \\
\hline Group B & 26.81 & 6.71 & & \\
\hline
\end{tabular}


Table III: Post-operative pain relief in Group A and Group B

\begin{tabular}{|c|c|c|c|c|c|}
\hline \multicolumn{6}{|c|}{ POST OPERATIVE PAIN RELIEF } \\
\hline VAS & GROUPS & MEAN & $\begin{array}{c}\text { STD. } \\
\text { DEVIATION }\end{array}$ & T VALUE & P VALUE \\
\hline \multirow{2}{*}{ 2nd Hour } & Group-A & 1.6 & 0.71 & \multirow{2}{*}{-3.203} & \multirow{2}{*}{$\mathrm{P}<0.002$} \\
\hline & Group-B & 2.28 & 0.79 & & \\
\hline \multirow{2}{*}{ 4th Hour } & Group-A & 2.84 & 1.03 & \multirow{2}{*}{-1.527} & \multirow{2}{*}{$\mathrm{P}<\mathbf{0 . 1 3 3}$} \\
\hline & Group-B & 3.2 & 0.58 & & \\
\hline \multirow{2}{*}{ 6th Hour } & Group-A & 4.2 & 1 & \multirow{2}{*}{-0.928} & \multirow{2}{*}{$\mathbf{P}<\mathbf{0 . 3 5 8}$} \\
\hline & Group-B & 4.44 & 0.82 & & \\
\hline
\end{tabular}

analogue scale (VAS) at 2nd, 4th and 6th post-operative hour, for the calculation of post-operative pain (Table III). The $\mathrm{P}$ value for the 2 nd post-operative hour was $<0.002$ (significant). Whereas, the $\mathrm{P}$ value for 4 th and 6th post-operative hour was $<0.133$ and $<0.358$, respectively (non-significant). (Fig. 3)

The $p$ value results of duration of surgery and the total blood loss during the surgery was not significant, and it implies that the infiltration of $2 \%$ lignocaine with 1:2,00,000 adrenaline doesn't have any significant advantage in the variables mentioned above.

Whereas, the $\mathrm{P}$ value for the 2 nd post-operative hour was significant implying that, the infiltration of $2 \%$ lignocaine with 1:2,00,000 adrenaline has an impact in decreasing pain 2 hours post operatively. And the 4th and 6 th post-operative pain scores were not significant, implying that, the infiltration of $2 \%$ lignocaine with $1: 2,00,000$ adrenaline has an impact in decreasing pain till 2 hours post operatively, but not later than that.

\section{Discussion}

Lignocaine is an amide linked local anaesthetic agent, which has an intermediate potency and duration, when compared to the other local anaesthetic drugs.
Percentage of lignocaine used for infiltration varies from 0.5 to $2 \%{ }^{3}$ The duration of action of $2 \%$ Lidocaine for infiltrative anaesthesia is 1 hour without addition of adrenaline. ${ }^{4}$ The onset of action of lignocaine is 3 minutes. Dose of lignocaine used for infiltration is $5 \mathrm{mg} /$ $\mathrm{kg}$ (without adrenaline) and $7 \mathrm{mg} / \mathrm{kg}$ (with adrenaline). ${ }^{5}$ The adverse effects of lignocaine are drowsiness, mental clouding, altered taste and tinnitus. Overdose causes muscle twitching, convulsions, cardiac arrhythmia, fall in $\mathrm{BP}$, coma and respiratory arrest.

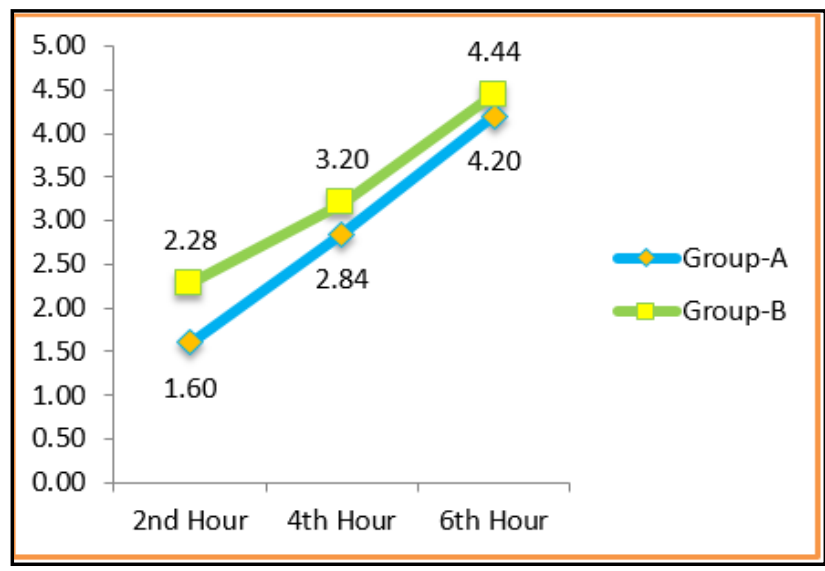

Fig. 3. Line diagram representing the post-operative pain score in Group A and Group B 
Vasoconstrictors example, adrenaline in the concentration of $1: 50,000$ to $1: 2,00,000$ added with lignocaine. The advantages of adding are prolongation of the duration of action of lignocaine to 2 hours, decreases the systemic toxicity by decreasing the absorption into systemic circulation and provides a bloodless surgical field. But the disadvantages include increased chances of subsequent tissue edema and necrosis and poor wound healing. This may raise the BP and promote arrhythmia in susceptible individuals. ${ }^{3}$

Senthil, Samuel, Ramachandran showed that infiltration of $2 \%$ lidocaine with adrenaline has a significant impact over the 1 st hour post-operative pain score and grade of bleeding in the surgical field, than using adrenaline alone in micro ear surgeries performed under general anaesthesia. But it does not have any influence over 4 th and 24th hour post-operative pain score. ${ }^{6}$ In our study we found that, infiltration of $2 \%$ lignocaine with 1:2,00,000 adrenaline has a significant impact over 2 nd post-operative hour pain score, but no impact with total amount of blood loss and 4th and 6th post-operative hour pain score.

The post-operative pain relief after surgery is due the pre-emptive analgesic effect of the local anaesthesia. Woolf and Chong did a study on preemptive analgesia - treating post-operative pain by preventing the establishment of central sensitization. Peripheral tissue injury during surgery provokes two kinds of modification in the responsiveness of nervous system. One is peripheral sensitization i.e, a reduction in threshold of nociceptor afferent from peripheral terminal and second is central sensitization, an activity dependent increase in excitability of spinal neurons. These changes contribute to the post-operative pain. Pre-emptive analgesia prevents central sensitisation and hyperexcitability of neurons. ${ }^{7}$ In our study we found that, the 2 nd post-operative hour pain relief effect is due to pre-emptive analgesia of lignocaine.

Kaufman et al. stated that the concomitant administration of LA and GA is safer than GA alone as evidenced by greater physiological stability in patients. Consideration should be given to combining pre-emptive analgesics or the concomitant use of LA with lighter levels of GA or sedation. This strategy is directed at achieving the highest degree of efficacy while simultaneously limiting the amount and magnitude of unwanted adverse effects that are associated with using any technique alone. The evidence is convincing that pre-operative pre-emptive LA or analgesic used with GA provides improved patient care and should be routinely considered. ${ }^{8}$ In our study also, we found the there was a good pain relief, post operatively in group of patients in whom we injected $2 \%$ lignocaine with $1: 2,00,000$ adrenaline.

The technique of infiltration of local anaesthetic drug has a bearing over the post-operative pain relief. Proper infiltration of local anaesthetic into the periosteum of the mastoid cortex needs a mention apart from regular subcutaneous infiltration. One of the reasons for persisting post-operative pain even after local anaesthetic infiltration is failure to infiltrate the periosteum. ${ }^{9}$ The same effect was proved in our study, with a proper infiltration of local anaesthetic into the periosteum, by giving a good pain relief for 2 hours post-operatively.

Hence we attribute that, the decreased intraoperative bleeding with sterile water infiltration maybe due to the right plane of infiltration in the periosteum. And the significant post-operative pain score at 2 nd postoperative hour is due to the pre-emptive analgesic effect of lignocaine infiltration.

In this study, an attempt is made to corroborate that, lignocaine with adrenaline infiltration does not have any added benefit in terms of per operative bleeding, when surgeries are performed under general anaesthesia. The limitation of our study is the sample size.

\section{Conclusion}

The infiltration of $2 \%$ lignocaine with $1: 2,00,000$ adrenaline in Type I Tympanoplasties, when done under general anaesthesia, has its own advantages and disadvantages. In our study we found that, there is no significant impact on infiltration of $2 \%$ lignocaine with 1:2,00,000 adrenaline in total blood loss during surgery and in 4th and 6th post-operative hour. But it is found that, $2 \%$ lignocaine with 1:2,00,000 adrenaline infiltration, gives good pain relief for 2 hours post operatively. 


\section{References}

1. Jackson CG. Principles of temporal bone \& skull basesurgery. 5th ed. In: Glasscock ME III, Gulya AJ (Eds) GlasscockShambaugh Surgery of Ear . Washington: BC Decker, 2003: p 264-74

2. Richard ML, Mounty CM. Critical care; electrolyte, acibbase balance; blood transfusion. In: Russell RCG, Norman SW, Christifer JKB (Eds) Bailey and Love's Short Practice of Surgery, 23rd ed. Arnold London, 2000: p 49

3. Tripathi KD. Essentials of Medical Pharmacology, 5th ed. New Delhi, Jaypee, 2001: p 325

4. Miller's RD. Anaesthesia, Vol 1, 6th ed. Philadelphia, Elsevier, 2005: p 582
5. Tripathi KD. Essentials of Medical Pharmacology, 5th ed. New Delhi, Jaypee, 2001: p 160-9

6. Senthil K, Samuel J, Ramachandran VV. Is Lidocaine infiltration really necessary in micro ear surgeries performed under general anaesthesia? Indian J Otolaryngol Head Neck Surg. 2012; 64(4):333-7; DOI 10.1007/s12070-011-0328

7. Woolf C, Chong MS. Pre-emptive analgesia treating postoperative pain by preventing establishment of central sensitisation. Anesth Analg.1993; 77(2):362-39

8. Kaufman E, Epstein JB, Gorsky M, Jackson DL, Kadari A. Pre-emptive analgesia and local anaesthesia as a supplement to general anaesthesia. Anesth Prog spring.2005; 52:29-38

9. Gottschalk A, Smith DS, Jobes DR, Kennedy SK, Lally SE et al. Pre-emptive epidural analgesia and recovery from radical prostatectomy-A randomised controlled trial. JAMA 1998; 279:1076-82 